\title{
Nicolau syndrome in a female patient following administration of intramuscular diclofenac injection: A case presentation
}

\author{
Ann Marie E. Edwards * \\ School of Nursing, University of the West Indies, Mona, Jamaica
}

Received: August 4, 2014

Accepted: November 3, 2014 Online Published: November 14, 2014

DOI: $10.5430 /$ cns.v3n1p37

URL: http://dx.doi.org/10.5430/cns.v3n1p37

\begin{abstract}
Introduction: Nicolau syndrome is a rare condition involving tissue necrosis as an adverse reaction to intramuscular preparations. The aim of this paper is to provide an understanding of Nicolau syndrome and its management.

Methods: Design: A case study approach was adopted. Setting: The study took place in a rural health centre in Jamaica West Indies. An audit of the client's medical record and interview with the client to obtain a history of the condition, followed by a comprehensive physical examination and laboratory testing. Synthesis of clinical and laboratory data as well as comparison of findings of similar cases done to confirm diagnosis.

Results: Findings illustrate severe tissue necrosis with residual effect following intramuscular injection of diclofenac.

Conclusions: The client had extensive tissue necrosis after receiving diclofenac injection which could be minimized with correct injection technique and early management of adverse reaction. This study provides valuable insight into the need for registered nurses, clinical nurse specialists, advanced practice nurses and doctors, to be knowledgeable of injection techniques, recognition of adverse effects of medications and the need for prompt specific management of adverse effects.
\end{abstract}

Key Words: Nicolau syndrome, Diclofenac injection, Z track technique

\section{Introduction}

It is rare for a client to present with substantial tissue necrosis after receiving an intramuscular (IM) injection. ${ }^{[1]}$ However, in Nicolau syndrome clients experience pain at the site soon after injection, followed by erythema, livedoid patch, hemorrhagic patch, and necrosis of skin, subcutaneous fat, and muscle tissue. ${ }^{[2,3]}$ The exact pathogenesis is unknown, but is thought to be associated with the inadvertent administration of an IM injection into an artery, resulting in vasospasm and emboli formation. ${ }^{[4]}$ Failure to use the Z-tract technique (see Figure 1) during IM administration, allows for contact of the medication with the subcutaneous tissue, resulting in cytotoxicity. Additionally the cytotoxic effect of diclofenac is also implicated in cases of Nicolau syndrome. ${ }^{[2]}$ Prompt intervention with drugs such as pentoxifylline and heparin is proven to reduce vasospasm and prevent emboli formation, thus arresting the development of the condition, while debridement is indicated for necrotic tissue. ${ }^{[5]}$ This paper describes a case of Nicolau syndrome in a middle aged female who received an intramuscular injection of diclofenac in a rural health center in Jamaica.

\footnotetext{
* Correspondence: Ann Marie E. Edwards; Email: anned3356@hotmail.com; Address: School of Nursing, University of the West Indies, 9 Gibraltar Camp Way, Mona Campus, Kingston 7, Jamaica.
} 

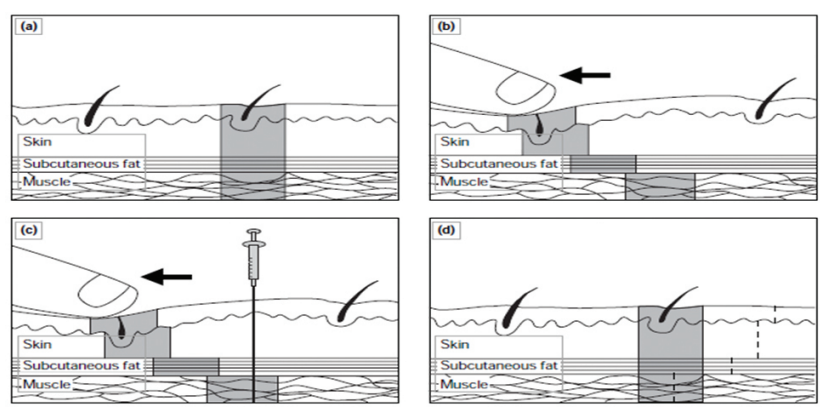

Figure 1: The $\mathrm{Z}$ track technique for intramuscular injection (1) Step 1: The skin, subcutaneous fat, and muscle lie in normal position. (2) Step 2: Pull the skin and subcutaneous layer $1 \mathrm{~cm}$ down to de-align with underlying muscle. (3) Step 3: Insert the needle at 90 degrees, inject and withdraw. (4) Step 4: Release the finger to break the needle track, trapping the drug inside the muscle (broken lines indicate the original needle track).

\section{Case presentation}

A 60 years old female adult with a history of hypertension and osteoarthritis received diclofenac injection $75 \mathrm{mg}$ intramuscularly in the upper outer quadrant of the left buttock for arthritic pains. The client developed sudden onset of sticking, burning, cramping, pain, rated $7 / 10$, localized to the injection site immediately upon receiving the injection. The pain progressed to an intensity of $9 / 10$ within 8 hours, and was associated with swelling, pallor, then blue/black discoloration of the skin at the affected site. The client reported no fever.

She returned to the Health Centre the second day post injection, complaining of burning, cramping and cold sensation at the injection site. She was reviewed by the medical officer and a diagnosis of allergic reaction to diclofenac made. Her treatment included paracetamol, chlorpheniramine and prednisolone tablets and she was reassured and sent home. She reported no effect from the medications as the intensity of the pain persisted.

By day 3-6, the client developed further darkening of the skin, bullae, warmth to site, and fever with rigors. She was seen by a private practitioner who prescribed antibiotics, analgesics and daily dressings, but her condition got progressively worst.

By day 10, a shallow ulcer developed which began at the margins of the hyperpigmented area on the buttock. She was treated at a hospital outpatient department with additional antibiotics and encouraged to continue daily dressings and analgesics. Despite treatment, the ulcer worsened, and was associated with persistent pain, and a tingling sensation radiating to the left leg. The fever subsided however. Her daily dressings continued, and she received repeated antibiotics with no apparent effect.

The client presented to the Family Nurse Practitioner three months after the onset of the condition with the above his- tory. Her past medical history revealed a diagnosis of hypertension for 15 years and osteoarthritis for five years. She reported no history of diabetes, hypercholesterolemia, peripheral vascular disease, sickle cell disease or known allergies.

Her physical examination revealed an anxious looking adult female of average built, in no obvious painful distress, but walked with a limping gait. She was anicteric, acyanotic, afebrile and her mucous membrane was pink and moist. She communicated intelligently. Except for a blood pressure of $150 / 90 \mathrm{mmHg}$, her cardiovascular system findings were normal. There was a partially healed, pale, sloughy ulcer approximately $5 \mathrm{~cm} \times 6 \mathrm{~cm}$ to the upper outer quadrant of her left buttock (see Figure 2). A $7 \mathrm{~cm}$ radius of hyperpigmented/hypopigmented scar tissue surrounded the ulcer but no discharge or malodour was noted. Although there was no swelling, redness or warmth to her joints, the range of motion in her left hip joint was decreased. The muscle strength in her left lower limb was also decreased, but all deep tendon reflexes appeared normal. Laboratory tests revealed elevated ALT, AST, Creatinine Kinase. A diagnosis of Nicolau syndrome was made based on her history and clinical presentation. Her wound was debrided and curiosin gel for daily dressing, vitamin B complex capsules, and pentoxyfylline tablets added to her treatment. The wound healed after three weeks with a dark disfiguring scar (see Figure 3). The limping gait persisted along with tingling and numbness to the left leg, so a diagnosis of peripheral neuropathy secondary to Nicolau syndrome was made and the client referred for neurological consultation.

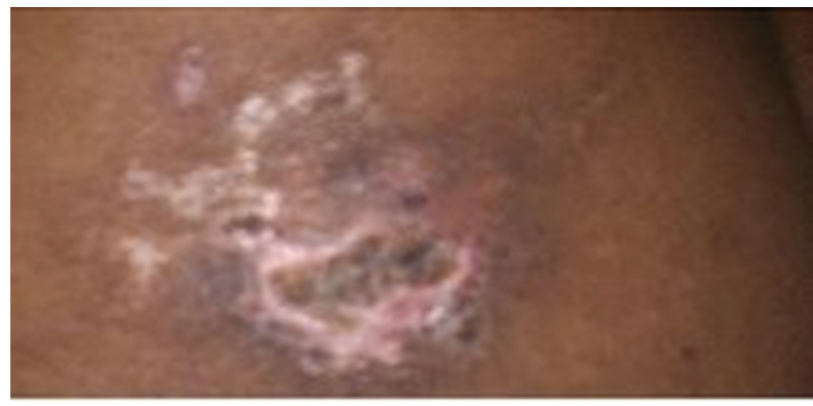

Figure 2: Partially healed ulcer with necrotic tissue in the upper outer quadrant of the left buttock (at the IM injection site of diclofenac), 3 months after the injection

\section{Discussion}

Nicolau syndrome is a rare adverse condition seen in clients who receive intramuscular injections including, corticosteroid, penicillin and agents such as diclofenac. ${ }^{[3]}$ According to the manufacturer ${ }^{[6]}$ diclofenac falls in the group of non-steroidal anti-inflammatory agents and is effective in relieving pain and inflammation is cases such as osteoarthritis. The injection form is formulated to be given intramuscularly or intravenously to clients experiencing acute pain. 
The maximum daily dose is $150 \mathrm{mg}$, but to avert the toxic effect of the drug, no more than $75 \mathrm{mg}$ ( 1 ampoule) is recommended to be given within a day. If two ampoules per day are required the alternative buttock should be used for the second. It is further emphasized that the injection be given deeply in the gluteal muscle in the upper outer quadrant of the buttocks, to avoid damage to nerve and other tissues. ${ }^{[6]}$ Diclofenac inhibits the enzyme cyclooxygenase and therefore causes vasospasm ${ }^{[7]}$ and it is suggested that vasospasm is a contributory factor in Nicolau syndrome. ${ }^{[4]}$ Additionally the toxic effect of the drug can augment the necrotic process. ${ }^{[8]}$ Because this client received IM diclofenac, she may have experienced some of these pathogeneses.

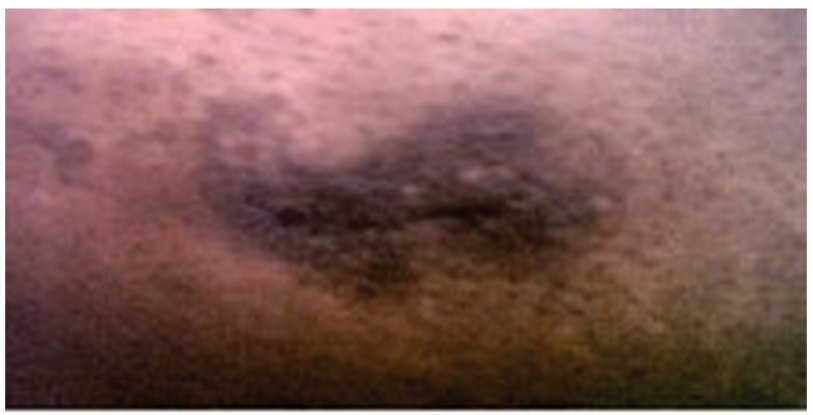

Figure 3: Healed area with hyperpigmented disfiguring scar tissue

Intramuscular injections should be administered using the $\mathrm{Z}$ track technique as the use of this technique will prevent administration of the drug into the subcutaneous tissue especially in obese clients. ${ }^{[2-9]}$ The client had a BMI of 24 which minimized the risk of the drug being administered into the subcutaneous tissue. However a survey conducted regarding the use of the $\mathrm{Z}$ track technique revealed that only two of 20 nurses working at the facility that the client received the injection understood and could explicitly explain the technique. It can be extrapolated therefore that this lack of knowledge resulted in a failure to use the technique in the administration of diclofenac to this client.

A confirmative diagnosis of Nicolau syndrome is based on history, clinical features and correlation with previous case reports. ${ }^{[3]}$ The client's laboratory tests reveal elevated AST,
ALT and creatine kinase which are makers of muscle damage but an increase in these markers do not automatically mean necrosis with muscle involvement. ${ }^{[3]}$ Although this client experienced severe pain, blanching of the skin, dark discoloration, bullae and rapidly progressing ulcer following the injection, the diagnosis of Nicolau syndrome was missed until 3 months after the onset. Magnetic Resonance Imaging (MRI) findings usually reveal the extent of necrosis $^{[10]}$ but no MRI was done.

An initial diagnosis of allergic reaction to diclofenac was made and the client was given prednisolone and chlorpheniramine tablets. Analgesics were continuously prescribed although they had little effect. One aim of treatment is to promptly improve the condition of the blood vessels to minimize necrosis and so drugs such as pentoxifylline and heparin are recommended. ${ }^{[5]}$ An audit of the client's record revealed that she did not receive these medications during the early stages of her condition. Debridement is suggested as a conservative measure to prevent complication in these clients. ${ }^{[10]}$ This client could have benefited more if this procedure was performed earlier.

\section{Conclusion}

Overwhelming evidence suggests that Nicolau Syndrome has devastating outcomes. The use of correct injection techniques will reduce incidences of the condition while early recognition and treatment will avert complications in clients receiving intramuscular preparations such as diclofenac. Deficiency in knowledge about the condition and its management pervades in our context. This case highlights the need for education of health professionals on early recognition and management of the condition.

\section{Recommendations}

The $\mathrm{Z}$ track technique is to be taught to all nursing and medical students. Periodic review of parenteral administrations should be done by health staff. Early interventions should be initiated to prevent complications in clients diagnosed with the Nicolau Syndrome. Continuing educational sessions should be conducted for health professionals to increase the awareness of this condition.

\section{References}

[1] Karimi M, Owlia M. Nicolau syndrome following intramuscular injection of penicillin. J Coll Physicians Surg Pak. 2012 Jan; 22(1): 41-42. PMid:22237189.

[2] Senel E. Nicolau syndrome as an avoidable complication. J Family Community Med. 2012 March 19; 19(1): 52-53. PMid:22518360. http://dx.doi.org/10.4103/2230-8229.94017

[3] Kwang-Kyoun K. Nicolau syndrome in patient following diclofenac administration: A case report. Ann Dermatol. 2011 Nov 3; 23(4): 501-503. PMid:22148020. http://dx.doi.org/10.5021 /ad.2011.23.4.501

[4] Murthy SC, Siddalingappa K, Suresh T. Nicolau's syndrome following diclofenac administration: A report of two cases. Indian J Dermatol Venereol Leprol. 2007 Nov-Dec; 73(6): 42931. PMid:18032871. http://dx.doi.org/10.4103/0378-632 3.37070

[5] Uri O, Arad E. Skin necrosis after self-administered intramuscular 
diclofenac. J Plast Reconstr Aesthet Surg. 2009 Feb 28; 1: 2.

[6] Diclofenac sodium injection [Package insert]. Trittau, Germany: Rotexmedica; 2000.

[7] Cakar M, Gündüz H, Kocayiğit I, et al. Acute coronary syndrome due to diclofenac potassium induced anaphylaxis: Two Kounis syndrome variants in the same patient. Anatol. J. Cardiol. 2011 Jan 11; 11(1): 88-9.

[8] Baykan H, Kuvat SV, Bozkurt M, et al. Tissue necrosis following intramuscular diclofenac injection. Dicle Medical Journal. 2010 Sept;
37(3): $300-301$

[9] Malkin B. Are techniques used for intramuscular injection based on research evidence? Nursing Times. 2008 Dec 16; 104(50/51): 4851. PMid:19165987.

[10] Nischal KC, Basavaraj HB, Swaroop MR, et al. Nicolau Syndrome: An Iatrogenic Cutaneous Necrosis. J Cutaneous Aesthet Surg. 2009 Dec 24; 2(2): 92-95. PMid:20808597. http://dx.doi.org/10. 4103/0974-2077.58523 